\title{
EVALUATION OF SHORT IMPLANTS' SUCCESS FOR TEETH REPLACEMENT IN ATROPHIC POSTERIOR MANDIBULAR RIDGE (CLINICAL TRIAL)
}

\author{
Fady M. Tadros*, Sameh A. Darwish ${ }^{* *}$ and Marwa G. Noureldin ${ }^{* * *}$
}

\begin{abstract}
Introduction: Atrophic mandibular jaws have been challenging to treat, using long implants. Techniques as jaw ridge augmentations, mandibular canal lateralization, and osseous distraction were proposed to allow the insertion of long Implants. However, complications as nerve injuries, tissue morbidity and prolonged healing have been inconvenient. Therefore, short implants with advanced surface treatments have been suggested.
\end{abstract}

Objectives: Clinical and radiographic evaluation of splinted and single short implants, before and after loading, for teeth replacement in atrophic posterior mandibular alveolar ridges.

Materials and Methods: A prospective study was done on 16 Patients with missing posterior teeth, with 6-8 $\mathrm{mm}$ of crestal height above the mandibular canal, and at least $7 \mathrm{~mm}$ of bone width. Group A: 8 patients received 2 short implants loaded by splinted crowns. Group B: 8 patients received single short implants loaded by single crowns. Osstell and CBCts were used for implant stability and bone condition assessment.

Results: Both groups maintained high implant stability with a mean of $(68.79 \pm 4.61)$ for group A and (71.71 \pm 3.55$)$ for group B, 6 months postoperative. Mean marginal bone loss for group A and group B was $(0.11 \pm 0.04)$ and $(0.16 \pm 0.10)$ respectively; however the difference is insignificant with $\mathrm{P}$ value 0.535 . A remarkable increase in bone density for both groups among the follow up time with $\mathrm{P}$ value $<0.001$ for both.

Conclusions: Short Implant is a useful solution for teeth replacement in atrophic posterior mandibular ridges, with an $87.5 \%$ of success recorded.

KEYWORDS: Short Implants, Splinted short Implants, Atrophic mandible, Crown-Implant ratio.

\footnotetext{
* Dentist at Ministry of Health, Alexandria, Egypt.

** Professor of Oral and Maxillofacial Surgery, Faculty of Dentistry, Alexandria University, Alexandria, Egypt.

*** Lecturer of Oral and Maxillofacial Surgery, Faculty of Dentistry, Alexandria University, Alexandria, Egypt.
} 


\section{INTRODUCTION}

The changes in alveolar ridge as a result of teeth extraction are named residual ridge resorption (RRR). The process of RRR is influential for the alveolar bone height as it is an irreversible process, with a nature of chronicity and progression ${ }^{(1)}$.

That makes anatomical structures as maxillary sinus and mandibular canal prone to injury during implant placement, and proposing short implants as a treatment choice.

In 1991 implants of 8 and 9 mm length were introduced and defined as "short." Thereafter implants being less than $7 \mathrm{~mm}$ in length are being described as short ${ }^{(2)}$.

The more desirable crown-implant ratio provided by longer implants has been the main reason for their choice as a more beneficial treatment modality compared to shorter implants ${ }^{(3)}$, in addition to the larger implant surface area available for osseointegration. Implants of $4 \mathrm{~mm}$ diameter and length of at least $10 \mathrm{~mm}$ became the norm and were considered the durable and safe option ${ }^{(4)}$, with 10 to $12 \mathrm{~mm}$ of residual alveolar bone thought to be the minimum requirement to ensure a predictable implant treatment.

However, in order to allow the placement of longer and/or wider implants in atrophic ridges, bone grafting techniques, alveolar distraction, and/or inferior alveolar nerve transposition were performed. Nevertheless, the use of short dental implants can now be considered a more suitable treatment for the current anatomy, as it offers many benefits, as the simplicity of implant insertion, easier surgical procedure, less traumatic procedure for the patients, shorter time needed for replacing the missing teeth and finally a more cost-effective solution compared to augmentations with lower expected complications.

The innovation of newer surface treatments techniques and the use of wider diameters of short implants, increased implant to bone contact exponentially, and consequently allowed a higher success for short implants. As preliminary implants had smooth surfaces, different techniques have been introduced to alter the topography of the implant surface, including acid etching, grit blasting, titanium plasma spraying, and deposition of nanoparticles. The result is increased surface roughness and consequently the implant surface area ${ }^{(5)}$ and they also have been found to accelerate osseointegration ${ }^{(6)}$.

According to force distribution along the implant surface, Lum found that occlusal forces applied to implants were distributed primarily to the crestal bone, regardless of implant length ${ }^{(7)}$.

Analysis made by Anitua et al., 2010 assessing the stress distribution among implants of different diameters, lengths and geometry, they discovered that most stresses are localized on the first six implant threads, regardless of the different varieties ${ }^{(8)}$.

That supports the reported results by studies that have found that neither implant length nor diameter dramatically affects the durability of short implants ${ }^{(9,10)}$.

Also, the idea of splinting crowns, for loading short implant was advised in order to reduce the lateral forces falling on the crowns and decrease stresses on the short implants ${ }^{(11)}$. Splinted crowns share stress with other implants because of the rigid union of components, thus enabling the stress distribution among the implants ${ }^{(12)}$.

\section{MATERIAL AND METHODS}

All study measures were approved by the Ethics research board, Faculty of Dentistry, Alexandria University. The study has been registered at clinicaltrials.gov with ID number: NCT04414709.

Study design: The study strategy was an interventional prospective clinical trial. 
Sample: Sixteen Patients with missing posterior mandibular teeth with atrophic alveolar ridges 6-8 $\mathrm{mm}$ above the mandibular canal and at least $7 \mathrm{~mm}$ width, indicated for short implant placement, were selected from the outpatient clinics of Oral and Maxillofacial Surgery Department, Faculty of Dentistry, Alexandria University, fulfilling all inclusion criteria, and received their treatment within the university clinics.

Sample size estimation: The minimal hypothesized total sample size was 16 patients, taking in consideration 5\% level of significance and $80 \%$ power using Chi-square-test (PASS program version 20).

\section{Inclusion criteria}

Inclusion criteria for the study population included the following: Patients had to be 30 to 60 years of age, with no gender predilection, with missing mandibular posterior teeth, indicated for short implant placement, residual alveolar ridge 6-8 $\mathrm{mm}$ height and at least $7 \mathrm{~mm}$ width. The patients chosen were medically fit, had good oral hygiene, and a healthy band of keratinized attached mucosa clinically approved.

\section{Exclusion criteria}

The exclusion criteria were the following: medically compromised and immunocompromised patients, smokers. Also, patients with poor oral hygiene and para-functional habits were excluded.

Patients fulfilling the criteria signed an informed consent form before undergoing the operation to ensure and confirm their understanding of the outcome of the operation and the risks they might be subjected to during the intervention.

\section{They were then divided into two groups:}

Group A: 8 patients received 2 short implants, loaded with splinted screw retained porcelain fused to metal crowns.
Group B: 8 patients received 1 short implant, loaded with single screw retained porcelain fused to metal crown.

The short implant fixtures used in study were standardized as DENTIUM superline implant fixture (Dentium, Korea) which is sandblasted with large grits and acid etched for surface treatment (S.L.A). The short implants used were of $7.0 \mathrm{~mm}$ length and $4.5 \mathrm{~mm}$ diameter. The Implants had $1.5 \mathrm{~mm}$ suprabony smooth collar, and $5.5 \mathrm{~mm}$ infra-bony surface treated double threaded titanium (Figure 1).

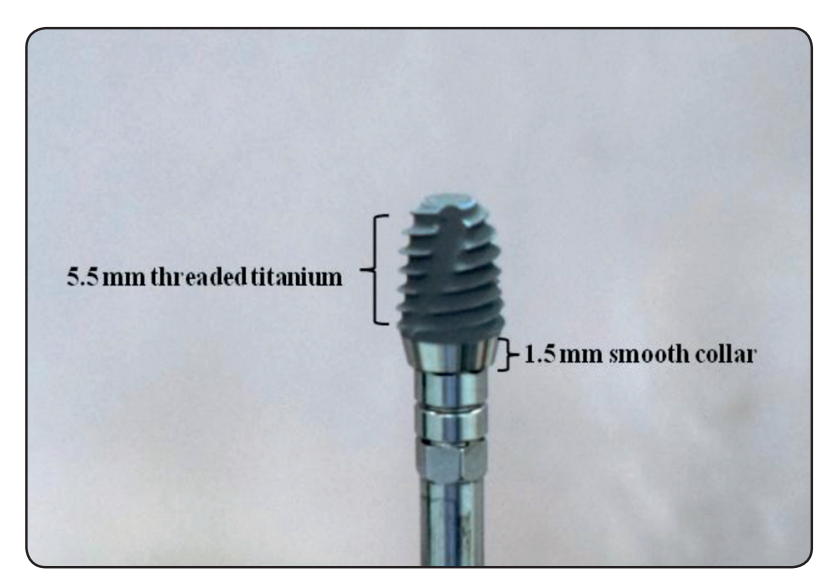

Fig. (1): Showing Dentiun 7mm short implant.

\section{Pre-surgical phase of treatment}

Patient assessment involved detailed medical, dental and social history taking. Clinical examination both intra and extra orally was held. Preoperative cone beam computed tomogram (CBCT) was taken with bone length and width measured, to assure it follows the inclusion criteria, as well as a record of bone density was taken in Hounsfield unit (HU), available by the (On Demand presentation system for the tomogram).

\section{Surgical phase of treatment}

For both groups, infiltration anesthesia articaine hydrochloride $4 \%$ used, and only crestal incisions used for crestal bone exposure. Implant osteotomies were prepared using Dentium Superline surgical 
kit, however underpreparation intended by skipping drilling by the final drill, just to preserve the bone, increase implant- bone contact, and increase implant stability. The implant stability quotient (ISQ) was recorded immediately after insertion using Osstell.

\section{Post-surgical phase of treatment}

It involved oral hygiene instructions, and prescribed medications: Amoxicillin clavulanate 1 gm (Augmentin, Glaxosmithkline, pharma, UK); 1 capsule every 12 hours for 5 days and Non-steroidal anti-inflammatory drugs: Ibuprofen $600 \mathrm{mg}$ (Brufen, Abbott, Egypt), 1 tablet 3 times daily after meals for 4 days.

\section{Prosthetic phase of treatment}

After 3 months postoperatively, Group A received 2 splinted screw retained porcelain fused to metal (PFM) crowns, while Group B received single screw retained (PFM) crown. ISQ was measured; CBCT was taken at this loading phase.

\section{Follow up phase}

Follow up was carried 3 months after loading, ISQ was recorded again, and another cone beam CT was taken for both groups (Figure 2).

\section{Outcome measurements}

1. Implant failure: implant loss, mobility or removal in case of progressive marginal bone loss, severe peri-implant infection or implant fracture. The implant failures were classified into two types: the early failures (or initial failures) before loading and the late failures after loading. The implant survivals were determined by the same method suggested by Buser et al., $1997^{(13)}$ and Cochran et al., $2002^{(14)}$.

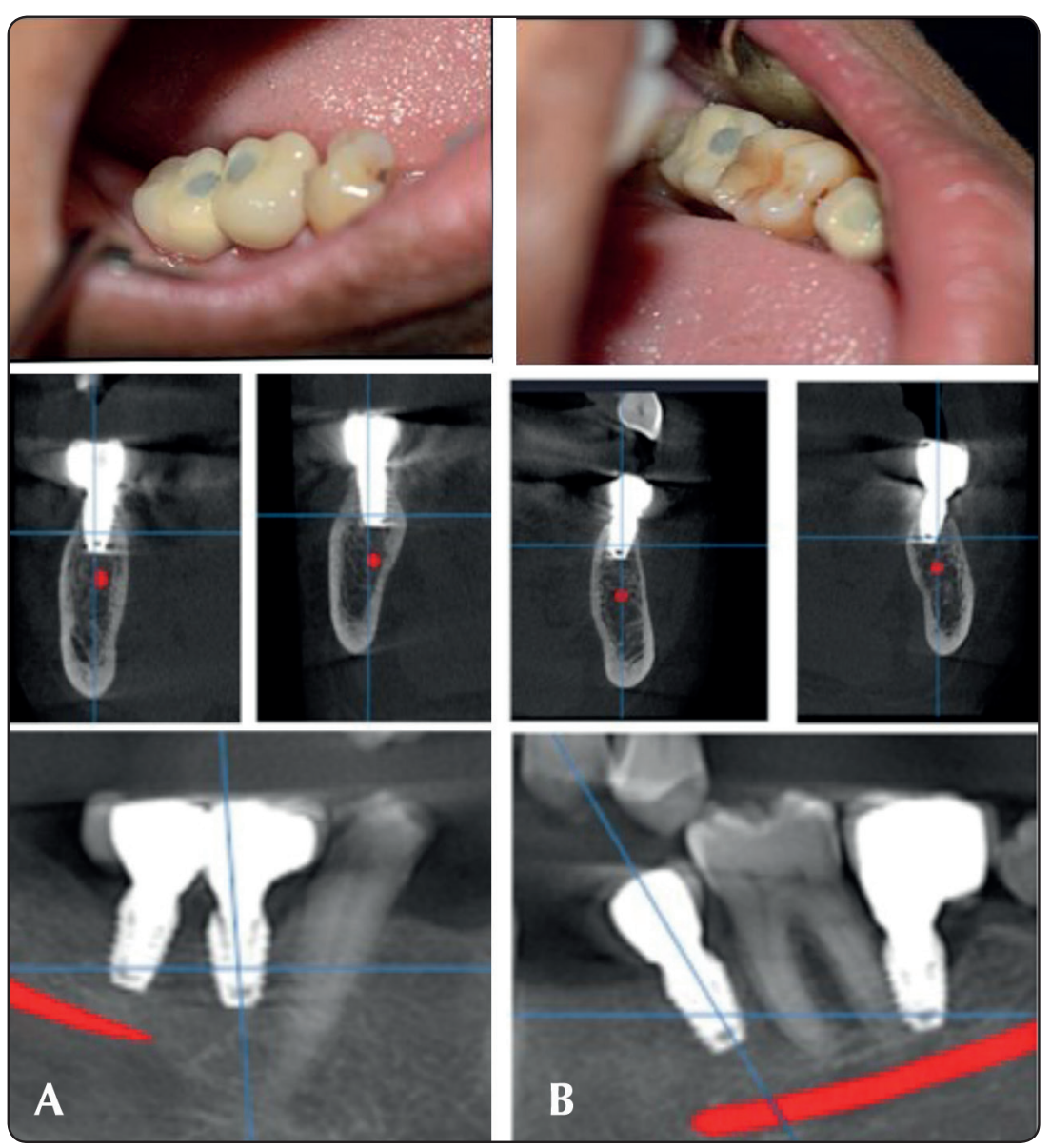

Fig. (2): Showing

A) 2 Short implants loaded by splinted crowns 6 months postoperative.

B) Short implants loaded by single crowns 6 months postoperative. 
a. Absence of clinically detectable implant mobility.

b. Absence of pain and subjective discomfort.

c. Absence of peri-implant infection.

d. Absence of continuous radiolucency around the implant.

Failed Implants were removed, with proper curetting for the implant osteotomy, to remove any granulation or necrotic tissue. Delayed implant placement was planned with patients to be 3 months later, taking into consideration the reasons of failure to avoid.

2. Peri-implant crestal bone loss was evaluated comparing CBCTs taken at delivery of the prostheses and 3 months after loading.

3. Implant stability (ISQ) measured by Osstell at implant placement, at loading and 3 months after loading.

4. Bone density at areas of implant placement, was assessed on the CBCTs taken preoperatively, at loading and 3 months after loading.

\section{Statistical analysis of the data}

Data were fed to the computer and analyzed using IBM SPSS software package version 20.0. (Armonk, NY: IBM Corp) Qualitative data were described using number and percent. The Kolmogorov-Smirnov test was used to verify the normality of distribution. Quantitative data were described using range (minimum and maximum), mean, standard deviation, median and interquartile range (IQR). Significance of the obtained results was judged at the $5 \%$ level.

\section{RESULTS}

The clinical trial was performed on sixteen patients, 11 males and 5 females. The Age of participants ranged from 30 to 60 years old with an average of (46.63 \pm 8.05$)$ years among Group A and an average of ( $50.50 \pm 7.76)$ years among Group B.

Clinically evaluating the participants during the treatment phases, there was little tolerable pain on the first postsurgical days during the follow up period (classified according to visual analogue scale 0-2 for all patients). Post-operative edema and patients' discomfort were mild (classified according to visual analogue scale as grade a or b for all patients). Healing was highly acceptable in all cases with no post-operative swelling or infection.

One recorded case with early failure, where a participant of Group A, had both her 2 short implants extruded and mobile, with signs of periimplant bone necrosis. Another case, in Group B had a late failure 3 months after loading, presented with implant mobility due to aggravated bone resorption. All failures were included in the study, with a net recorded success of $87.5 \%$.

Regarding to Group A; where 2 short implants inserted for each patient, the implants were placed with high stability, represented by high ISQ value of a mean $(69.75 \pm 7.58)$. Changes in stability at loading and 6 months postoperative for all Group A patients were insignificant ( $\mathrm{P}$ values 0.066 ) which indicates the maintenance of the high stability of the implants gained at insertion because of the under-preparation of the implant osteotomies during surgery. The mean of implant stability 6 months postoperatively was $(68.79 \pm 4.61)$. Regarding Group B; where the patients received a single short implant each, the average ISQ at placement was (71.38 \pm 7.44$)$. There was an insignificant increase at loading to $(72.50 \pm$ 2.67) followed by insignificant decrease to $(71.71 \pm$ $3.55)$ after loading. The $P$ value was 0.752 , which indicates that all changes in ISQ were insignificant and that the high implant stability at insertion was maintained among the other phases of loading and follow up. Comparing the achieved implant stability for both groups at all phases, immediately, 3 and 6 months postoperative were insignificant with $\mathrm{P}$ values $0.696,0.127,0.207$ respectively. (Table 1, Figure 3). 
The results for radiographic evaluation involved the assessment of bone density changes, and periimplant marginal bone level. There was a significant increase in bone density recorded for both groups, indicating a higher mineralized bone contact associating the osseointegration process of short implants. P value was less than 0.001 for both groups
(Table 2, Figure 4). While regarding the peri-implant marginal bone loss, crestal bone level changes after loading was compared to its level at loading. The mean peri-implant resorption for Group B was $(0.16$ $\pm 0.10)$ higher than that of Group A which was $(0.11$ $\pm 0.04)$, however statistically the difference was insignificant (P value is 0.535) (Table 3, Figure 5).

TABLE (1) Comparison between the two studied groups according to implant stability

\begin{tabular}{|c|c|c|c|c|}
\hline Implant stability & Group A & Group B & $\mathrm{t}$ & $\mathrm{p}$ \\
\hline ISQ at placement & $(\mathrm{n}=8)$ & $(\mathrm{n}=8)$ & \multirow{4}{*}{0.399} & \multirow{4}{*}{0.696} \\
\hline Min. - Max. & $58.50-84.0$ & $57.0-82.0$ & & \\
\hline Mean \pm SD & $69.88 \pm 7.58$ & $71.38 \pm 7.44$ & & \\
\hline Median (IQR) & $69.75(65.5-73.0)$ & $73.50(67.5-75.0)$ & & \\
\hline ISQ at loading & $(n=7)$ & $(\mathrm{n}=8)$ & \multirow{4}{*}{1.631} & \multirow{4}{*}{0.127} \\
\hline Min. - Max. & $65.0-73.50$ & $68.0-76.0$ & & \\
\hline Mean \pm SD & $70.0 \pm 3.27$ & $72.50 \pm 2.67$ & & \\
\hline Median (IQR) & $71.50(67.8-72.3)$ & $72.0(71.0-75.0)$ & & \\
\hline ISQ 3 months after loading & $(n=7)$ & $(n=7)$ & \multirow{4}{*}{1.333} & \multirow{4}{*}{0.207} \\
\hline Min. - Max. & $60.50-73.0$ & $68.0-76.0$ & & \\
\hline Mean \pm SD & $68.79 \pm 4.61$ & $71.71 \pm 3.55$ & & \\
\hline Median (IQR) & $71.0(66.5-72.0)$ & $70.0(69.0-75.0)$ & & \\
\hline
\end{tabular}

$t:$ Student t-test

p: p value for comparing between the studied groups

TABLE (2) Comparison between the two studied groups according to bone density

\begin{tabular}{|c|c|c|c|c|}
\hline Bone density & Group A & Group B & $\mathbf{t}$ & p \\
\hline Preoperative & $(\mathbf{n}=8)$ & $(\mathbf{n}=8)$ & \multirow{4}{*}{1.175} & \multirow{4}{*}{0.260} \\
\hline Min. - Max. & $231.41-482.81$ & $114.0-429.79$ & & \\
\hline Mean \pm SD & $369.69 \pm 76.43$ & $312.73 \pm 113.82$ & & \\
\hline Median (IQR) & 367.96(336.9-416.8) & $341.26(225.9-411.9)$ & & \\
\hline At loading & $(\mathrm{n}=7)$ & $(\mathbf{n}=8)$ & \multirow{4}{*}{0.955} & \multirow{4}{*}{0.357} \\
\hline Min. - Max. & $350.14-486.36$ & $260.31-506.23$ & & \\
\hline Mean \pm SD & $424.42 \pm 51.21$ & $390.66 \pm 80.09$ & & \\
\hline Median (IQR) & 420.69(395.5-461.4) & 413.32(327.3-438.8) & & \\
\hline 3 months after loading & $(\mathrm{n}=7)$ & $(\mathrm{n}=7)$ & \multirow{4}{*}{0.965} & \multirow{4}{*}{0.353} \\
\hline Min. - Max. & $370.64-498.42$ & $310.68-532.24$ & & \\
\hline Mean \pm SD & $449.03 \pm 50.38$ & $417.06 \pm 71.67$ & & \\
\hline Median (IQR) & 470.25(416.4-485.6) & $420.36(378.1-450.0)$ & & \\
\hline$P$ value & $<0.001^{*}$ & $<0.001^{*}$ & & \\
\hline
\end{tabular}

t: Student t-test

p value: $p$ value for comparing between the studied periods

p1: p value for comparing between the studied groups

*: Statistically significant at $p \leq 0.05$ 
TABLE (3) Comparison between the two studied groups according to marginal bone loss.

\begin{tabular}{|c|c|c|c|c|}
\hline Bone loss & $\begin{array}{c}\text { Group A } \\
(\mathbf{n}=7)\end{array}$ & $\begin{array}{c}\text { Group B } \\
(\mathbf{n}=7)\end{array}$ & $\mathbf{U}$ & $\mathbf{p}$ \\
\hline Buccal crestal & & & \multirow{4}{*}{19.00} & \multirow{4}{*}{0.535} \\
\hline Min. - Max. & $0.04-0.24$ & $0.05-0.41$ & & \\
\hline Mean \pm SD & $0.12 \pm 0.06$ & $0.18 \pm 0.13$ & & \\
\hline Median (IQR) & $0.10(0.10-0.15)$ & $0.15(0.09-0.23)$ & & \\
\hline Lingual crestal & & & \multirow{4}{*}{9.00} & \multirow{4}{*}{0.053} \\
\hline Min. - Max. & $0.00-0.13$ & $0.04-0.52$ & & \\
\hline Mean \pm SD & $0.05 \pm 0.05$ & $0.17 \pm 0.16$ & & \\
\hline Median (IQR) & $0.03(0.01-0.10)$ & $0.12(0.08-0.18)$ & & \\
\hline Mesial crestal & & & \multirow{4}{*}{20.5} & \multirow{4}{*}{0.620} \\
\hline Min. - Max. & $0.03-0.14$ & $0.03-0.23$ & & \\
\hline Mean \pm SD & $0.10 \pm 0.04$ & $0.13 \pm 0.08$ & & \\
\hline Median (IQR) & $0.12(0.10-0.13)$ & $0.12(0.06-0.20)$ & & \\
\hline \multicolumn{5}{|l|}{ Distal crestal } \\
\hline Min. - Max. & $0.02-0.16$ & $0.03-0.24$ & \multirow{3}{*}{18.0} & \multirow{3}{*}{0.456} \\
\hline Mean \pm SD & $0.10 \pm 0.05$ & $0.14 \pm 0.08$ & & \\
\hline Median (IQR) & $0.12(0.08-0.13)$ & $0.12(0.08-0.21)$ & & \\
\hline \multicolumn{5}{|l|}{ Average peri-implant } \\
\hline Min. - Max. & $0.05-0.15$ & $0.04-0.34$ & \multirow{3}{*}{19.00} & \multirow{3}{*}{0.535} \\
\hline Mean \pm SD & $0.11 \pm 0.04$ & $0.16 \pm 0.10$ & & \\
\hline Median (IQR) & $0.11(0.08-0.14)$ & $0.11(0.10-0.21)$ & & \\
\hline
\end{tabular}

U: Mann Whitney test

p: $p$ value for comparing between the studied groups

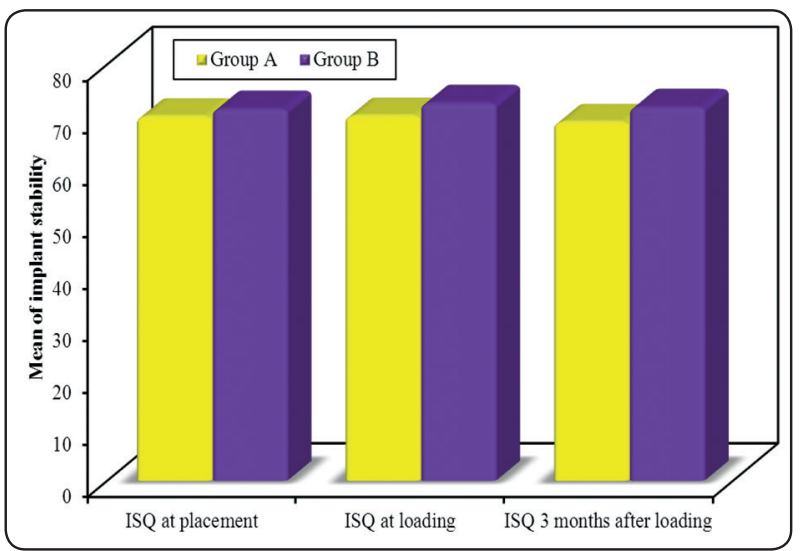

Fig. (3): Comparison between the two studied groups according to implant stability.

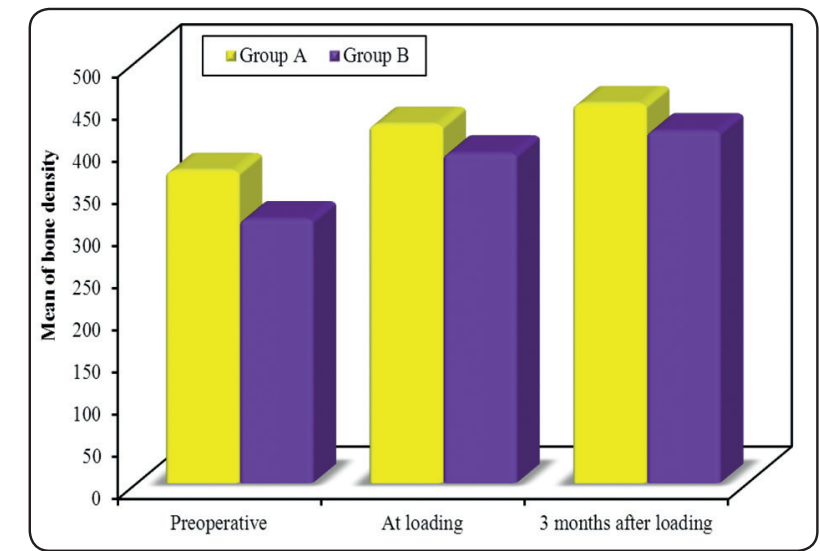

Fig. (4): Comparison between the two studied groups according to bone density 


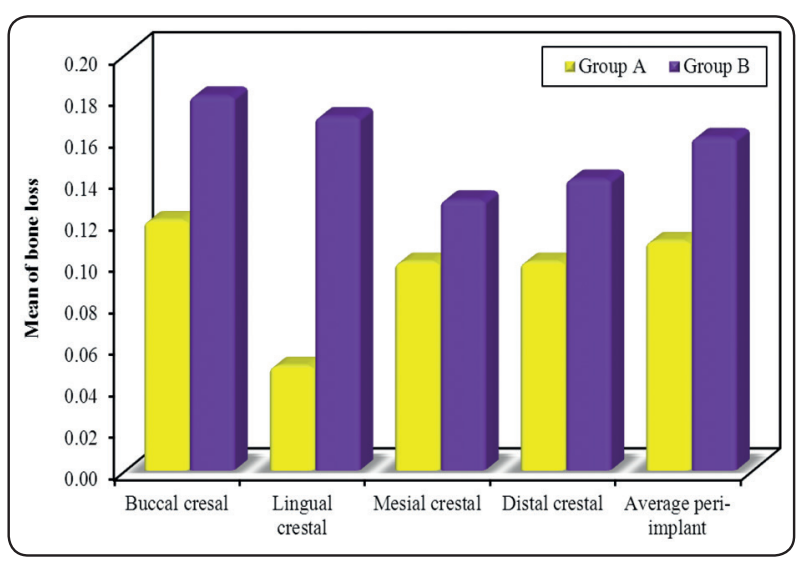

Fig. (5): Comparison between the two studied groups according to bone loss.

\section{DISCUSSION}

The present prospective clinical trial reported the outcome of two splinted crowns (Group A) and single crown (Group B), supported by $7 \mathrm{~mm}$ short Implants. Two patients recorded failures, one in each group with a total of three implants were lost; two implants were lost before loading for a Group A patient and one after loading by single crown for a Group B patient. This represents a success rate of $87.5 \%$ for the 24 inserted short implants. This percentage of success is much lower than the $98.9 \%$ recorded by Misch et al., $2006^{(15)}$ This may be of the use of both $7 \mathrm{~mm}$ and $9 \mathrm{~mm}$ implants in the study by Misch. Also, $99.1 \%$ was reported as an additive survival for six thousand one hundred ninety three implants in a systematic review by Annibali ${ }^{(16)}$. The variation in results may be of the dramatic difference in sample size, as well as the inclusion of both long implants and short implants in Annibali's review. However, the results of this trial is close to that of Friberg et al., ${ }^{(17)}$ and Lekholm et al., ${ }^{(18)}$ which reported $92.3 \%$ and $93.5 \%$ of survival rate respectively for short implants less than or equal to $7 \mathrm{~mm}$ of length, after 10 years of short implants placement.

To attain short implant insertion in Type III and Type IV bone sites with high stability and torque, Amato F has recommended under-preparation of the osteotomy which was followed in the surgical phase of the clinical trial ${ }^{(19)}$. The insignificant change in implants stability throughout the clinical trial and maintenance of the high stability even after loading (P value 0.066 for Group A, and 0.752 for Group B) agrees with Amato $\mathrm{F}$ recommendations. Although others may be apprehensive about the higher insertion torque and excessive stability that may be accused for a phenomenon called "osseous pressure necrosis" (20-22), where excessive compressive stress leads to blood vessels obstruction which can limit the bone perfusion surrounding the implant and induce bone necrosis.

This may be the cause for patient in Group A losing her two implants before loading since that implants were placed with ISQ more than 80 .

The Implant used in study has a sand blasted, acid etched (SLA) surface treatment. In the SLA method, $\mathrm{TiO} 2$ and $\mathrm{A} 12 \mathrm{O} 3$ like particles are used for the abrasion of the surface. The rough surface has more surface energy when compared to a smooth surface. Thus, the SLA technique can accelerate as well as improve the process of osseointegration ${ }^{(23)}$. This ultimately improves the mechanical stability of the implant. This matches the results of the study, as the short implants maintained the high stability since insertion and throughout the study phases. The average ISQ 6 months postoperatively was $(68.79 \pm$ 4.61) for Group A and (71.71 \pm 3.55$)$ for Group B.

In Group B, the failure of the implant after loading may be attributed to the inadequate crown/ implant ratio, given that it exceeded 1.4 for this patient. The average crown/implant ratio was 0.90 and 0.94 for Group A and Group B respectively. The crown-height space is an anatomical parameter that is defined as the distance between the occlusal plane and the bone crestal margin. For each $1 \mathrm{~mm}$ increase in crown-height space, the load on the cervical portion of implant rises by $20 \%{ }^{(24)}$. A shorter implant has a larger crown/implant ratio in comparison to a longer implant with the same 
crown height. Therefore, complications should be expected in short implants. Our findings completely agrees with Nissan et al., (24) results, reported in 2011. On the other hand, it disagrees with Blanes et al., 2007 where 192 non submerged ITI implants, reported a mean clinical crown/implant ratio of 1.77 , with 51 implants exhibiting crown/implant ratios greater than or equal to 2.0 and $13.5 \%$ of the restorations utilized in the mentioned study were single-tooth non-splinted restorations (25). In this study, only 3 Implants failed within 1 year of placement to provide a cumulative success of $94.1 \%$ and a conclusion that implant restorations with crown/implant ratios between 2 and 3 may be successfully used in the posterior areas of the jaw.

There was a significant increase in bone density 3 and 6 months postoperatively in comparison to preoperative state. $\mathrm{P}$ value for both groups was less than 0.001 comparing the change in bone density among all study phases. There was a significant increase in bone density 3 months postoperatively compared to preoperative state, with $\mathrm{P} 1$ value 0.015 for Group A and 0.008 for Group B. This may be due to the under-sizing of drilling (underpreparation of implant osteotomy) and depending on implant's bone expanding capability. This technique helps in condensing the bone and compressing the trabecular spaces there by preserving the bone and consequently increasing the quality or density of bone. These results correlate with the studies conducted by Fanuscu et al., (26) in cadaver bone where expansion technique resulted in notable change in peri-implant bone architecture and significant increase in bone density. Also, the results agree with studies stating that the rough implant topography favor new bone deposition directly on the implant surface (direct osteogenesis or de novo bone formation) which consequently allows the rise in bone minerals volume and density ${ }^{(27)}$. Comparing the increase in bone density changes between both Groups, the difference was insignificant, $(\mathrm{P}=0.357)$ 3 months postoperatively and $(\mathrm{P}=0.353) 6$ months postoperatively.
Splinted and single implants were assessed with mean marginal peri-implant bone loss was higher for single implants $(0.16 \pm 0.10) \mathrm{mm}$ compared to splinted ones $(0.11 \pm 0.04) \mathrm{mm}$. However the difference was statistically insignificant $(\mathrm{P}$ value $=$ 0.535). This disagrees with other previous studies stating that splinted crowns share stress with other implants because of the rigid union of components, thus enabling the stress distribution among the implants ${ }^{(28)}$ resulting in reducing the stress on implants that are under a high yield of masticatory forces, such as those inserted in the molar region. The variation in this trial result compared to other studies may be due to the short period of follow up, and restricted sample size compared to others.

Finally, in this study the null-hypothesis has been rejected, since an evident clinical and radiographic change has been recorded proving $87.5 \%$ of success for the placed short implants for both Group A and $\mathrm{B}$, with comparable results. The percentage seems lower than those recorded in other studies due to the limitation of the sample size; however promising result has been achieved proving a solid base for the use of short implants for replacement of missing posterior teeth in atrophic mandibular ridges. It is advised that further studies should be carried, with larger sample size and longer periods of follow up, to provide evidence of higher level and convenience, for short implant choice as a treatment modality over augmentation and conventional implant insertion.

\section{CONCLUSION}

Within the limitation of the study, the following could be concluded:

1. Short Implant is a useful solution for teeth replacement in atrophic posterior mandibular ridges, with $87.5 \%$ of success recorded.

2. The crown height is a parameter that should be assessed before choosing short implants as a restorative solution. Crown/Root ratio must not exceed 1.0. 
3. The ISQ for implants inserted for delayed loading should not exceed 80 especially with reduced osteotomy to avoid osseous pressure necrosis.

\section{CONFLICT OF INTEREST}

The authors declare that they have no conflicts of interest.

\section{ACKNOWLEDGEMENTS}

A debt of gratitude is owed to all professors and colleagues at the Oral and Maxillofacial department, Faculty of Dentistry, Alexandria University for their encouragement, support and advices, throughout the study.

\section{FUNDING}

The author received no specific funding for this work, to be completely independent of any influence on study results collection or publication.

\section{REFERENCES}

1- Kumar TA, Naeem A, Verma AK, Mariyam A, Krishna D, Kumar PK. Residual ridge resorption: The unstoppable. Int J Appl Res. 2016;2:169-71.

2- Hagi D1, Deporter DA, Pilliar RM, Arenovich T. A targeted review of study outcomes with short $(<$ or $=7 \mathrm{~mm})$ endosseous dental implants placed in partially edentulous patients. J Periodontol. 2004;75:798-804.

3- Glantz PO, Nilner K. Biomechanical aspects of prosthetic implantbone reconstructions. Periodontol 2000. 1998; 17:119-24.

4- Renouard F, Nisand D. Short implants in the severely resorbed maxilla: A 2-year retrospective clinical study. Clin Implant Dent Relat Res. 2005;7:104-10.

5- Al-Hashedi AA, Talyeb Ali TB, Yunus N. Short dental implants: An emerging concept in implant treatment. Quintessence Int. 2014;45;499-514.

6- Misch CE, Steignga J, Barboza E, Misch-Dietsh F, Cianciola LJ, Kazor C. Short dental implants in posterior partial edentulism: A multicenter retrospective 6-year case series study. J Periodontol. 2006;77:1340-7.
7- Lum LB. A biomechanical rationale for the use of short implants. J Oral Implantol. 1991;17:126-31.

8- Anitua E, Tapia R, Luzuriaga F, Orive G. Influence of implant length, diameter and geometry on stress distribution: A inite element analysis. Int J Periodontics Restorative Dent. 2010;30:89-95.

9- Monje A, Fu JH, Chan HL, Suarez F, Galindo-Moreno $\mathrm{P}$, Catena A, et al. Do implant length and width matter for short dental implants $(<10 \mathrm{~mm})$ ? A meta-analysis of prospective studies. J Periodontol. 2013;84:1783-91.

10- Tawil G, Younan R. Clinical evaluation of short, machinedsurface implants followed for 12 to 92 months. Int J Oral Maxillofac Implants. 2003;18:894-901.

11- Pierrisnard L, Renouard F, Renault P, Barquins M. Influence of implant length and bicortical anchorage on implant stress distribution. Clin Implant Dent Relat Res. $2003 ; 5: 254-62$.

12- Lemos CAA, Verri FR, Santiago JF Júnior, Almeida DAF, Batista VES, Noritomi PY, et al. Retention system and splinting on morse taper implants in the posterior maxilla by 3D finite element analysis. Braz Dent J. 2018;29:30-5.

13- Buser D, Mericske-Stern R, Bernard JP, Behneke A, Behneke N, Hirt HP, et al. Long-term evaluation of nonsubmerged ITI implants. Part 1: 8-year life table analysis of a prospective multi-center study with 2359 implants. Clin Oral Implants Res. 1997;8:161-72.

14- Cochran DL, Buser D, ten Bruggenkate CM, Weingart D, Taylor TM, Bernard JP, et al. The use of reduced healing times on ITI implants with a sandblasted and acidetched (SLA) surface: early results from clinical trials on ITI SLA implants. Clin Oral Implants Res. 2002;13:144-53.

15- Misch CE, Steignga J, Barboza E, Misch-Dietsh F, Cianciola LJ, Kazor C. Short dental implants in posterior partial edentulism: a multicenter retrospective 6-year case series study. J Periodontol. 2006;77:1340-7.

16- Annibali S, Cristalli MP, Dell'Aquila D, Bignozzi I, La Monaca G, Pilloni A. Short dental implants: a systematic review. J Dent Res. 2012;91:25-32.

17- Friberg B, Gröndahl K, Lekholm U, Brånemark PI. Longterm follow-up of severely atrophic edentulous mandibles reconstructed with short Brånemark implants. Clin Implant Dent Relat Res. 2000;2:184-9.

18- Lekholm U, Gunne J, Henry P, Higuchi K, Lindén U, Bergström C, et al. Survival of the Brånemark implant in 
partially edentulous jaws: a 10-year prospective multicenter study. Int J Oral Maxillofac Implants. 1999;14:639-45.

19- Amato F, Polara G. A prospective evaluation of a novel implant designed for immediate loading. Int J Periodontics Restorative Dent. 2014;34:43-9.

20- Winwood K, Zioupos P, Currey JD, Cotton JR, Taylor $\mathrm{M}$. The importance of the elastic and plastic components of strain in tensile and compressive fatigue of human cortical bone in relation to orthopaedic biomechanics. J Musculoskelet Neuronal Interact. 2006;6:134-41.

21- Haider R, Watzek G, Plenk Jr H. Histomorphometric analysis of bone healing after insertion of IMZ-1 implants independent of bone structure and drilling method. Z Stomatol. 1991;88:507-21.

22- Bashutski JD, D'Silva NJ, Wang HL. Implant compression necrosis: current understanding and case report. J Periodontol. 2009;80:700-4.

23- Rosales-Leal JI, Rodríguez-Valverde MA, Mazzaglia G, Ramón-Torregrosa PJ, Díaz-Rodríguez L, GarcíaMartínez O, et al. Effect of roughness, wettability and morphology of engineered titanium surfaces on osteoblastlike cell adhesion. Colloids Surf, A Physicochem Eng Asp. 2010;365:222-9.
24- Nissan J, Ghelfan O, Gross O, Priel I, Gross M, Chaushu G. The effect of crown/implant ratio and crown height space on stress distribution in unsplinted implant supporting restorations. J Oral Maxillofac Surg. 2011;69:1934-9.

25- Blanes RJ, Bernard JP, Blanes ZM, Belser UC. A 10-year prospective study of ITI dental implants placed in the posterior region. II: Influence of the crown-to-implant ratio and different prosthetic treatment modalities on crestal bone loss. Clin Oral Implants Res. 2007;18:707-14.

26- Fanuscu MI, Chang TL, Akça K. Effect of surgical techniques on primary implant stability and peri-implant bone. J Oral Maxillofac Surg. 2007;65:2487-91.

27- Meyer U, Joos U, Mythili J, Stamm T, Hohoff A, Fillies $\mathrm{T}$, et al. Ultrastructural characterization of the implant/ bone interface of immediately loaded dental implants. Biomaterials. 2004;25:1959-67.

28- Lemos CAA, Verri FR, Santiago JF Júnior, Almeida DAF, Batista VES, Noritomi PY, et al. Retention System and Splinting on Morse Taper Implants in the Posterior Maxilla by 3D Finite Element Analysis. Braz Dent J. 2018;29:30-5. 